\title{
Proliferative activity of neuroendocrine tumours of the gastroenteropancreatic endocrine system: DNA flow cytometric and immunohistological investigations
}

Institute of Pathology

A von Herbay

B Sieg

W J Hofmann

H F Otto

and Department of

Surgery, University of

Heidelberg, Germany

G Schürmann

M Betzler

Correspondence to:

Dr Axel von Herbay,

Pathologisches Institut,

Universität Heidelberg, Im

Neuenheimer Feld 220/221,

D-6900 Heidelberg 1,

Germany.

Accepted for publication

17 September 1991

\author{
A von Herbay, B Sieg, G Schürmann, W J Hofmann, M Betzler, H F Otto
}

\begin{abstract}
The proliferative activity of 16 tumour specimens from 13 patients with neuroendocrine tumours of the gastroenteropancreatic endocrine system was studied by DNA flow cytometry and immunohistology for the nuclear Ki67 proliferation antigen. Equivalent results were obtained with both methods, which showed the proliferative activity of gastroenteropancreatic neuroendocrine tumours to be heterogeneous. In four malignant small intestinal carcinoids and one extravisceral carcinoid localised in the retroperitoneum the percentage (index) of proliferating tumour cells as measured by DNA flow cytometry ranged from 2.9 to $36 \cdot 2 \%$ corresponding to low, moderate, or high proliferative activity. In four malignant pancreatic endocrine tumours and their metastases indices ranged from 8.7 to $18 \cdot 3 \%$, corresponding to low, moderate, or high proliferative activity. In four benign pancreatic endocrine tumours indices ranged from 4.3 to $7 \cdot 7 \%$, all corresponding to low proliferative activity. This heterogeneity of proliferative activity may in part explain the heterogeneous results reported of chemotherapy treatment. As chemotherapy of tumours is largely affected by favourable cell cycling kinetics, individual diagnostic investigations of the proliferative activity of these neuroendocrine tumours may be of value for identifying patients suitable for this treatment.
\end{abstract}

The biology of neuroendocrine tumours of the gastroenteropancreatic endocrine system ${ }^{1}$ is characterised by autonomous hormone synthesis and secretion that typically result in peculiar hormonal syndromes, ${ }^{23}$ and by autonomous growth. While several experimental and clinical studies have focused on the autonomous hormone production of these endocrine tumours, ${ }^{4}$ far less is known about their growth behaviour.

Commensurate with our incomplete knowledge of the biology of these tumours, medical (non-surgical) treatment of gastroenteropancreatic neuroendocrine tumours is at present more effective in controlling the hormonal activity than the autonomous growth of the tumour. Previous attempts at antineoplastic chemotherapy met with mixed success, ${ }^{5}$ and each patient's response is considered unpredictable. More recent approaches with hormone treatment using the somatostatin analogue octreotide (SMS 201-995) have not yet provided convincing evidence that octreotide is effective in controlling tumour growth, ${ }^{6}$ and the results of treatment with interferon alfa are also controversial. ${ }^{7 \mathrm{a}} 8$

Since the growth of gastroenteropancreatic neuroendocrine tumours is not yet understood we studied the proliferative activity of benign and malignant gastroenteropancreatic neuroendocrine tumours using two different approaches.

\section{Methods}

A total of 16 tumour specimens (primary tumour and metastases) obtained from 13 patients with gastroenteropancreatic neuroendocrine tumours were investigated. The Table gives details of the patients. There were six men and seven women, median age of 47 years (range $31-63$ years). All patients were treated by primary tumour resection. In addition, patients 6,7 , and 8 had hemihepatectomy or enucleation of many liver metastases, or both. No antiproliferative medical treatment was performed before surgery in any patient with metastatic tumours. All specimens used in this study were taken from the tumour margins of the fresh surgical specimen.

The diagnosis of neuroendocrine tumours was established on the basis of the typical histology in all cases and was confirmed by immunohistological study of the neuroendocrine cell markers chromogranin $A$ and neuron-specific $\gamma$-enolase. ${ }^{9}$ Hormonal activity was diagnosed in six cases when preoperative serum or urinary findings, immunohistological findings in the tumour tissue, and the clinical findings were in agreement. In one case (patient 9) hormonal activity remained questionable where a fivefold rise in serum glucagon was found once before operation but only a few tumour cells were glucagon immunoreactive, and the glucagonoma syndrome was absent. Six tumours were considered .hormonally inactive, including a case (patient 5) in which tumour tissue was serotonin immunoreactive but urinary measurements of 5-hydroxyindole acetic acid were normal, and the carcinoid syndrome was absent.

Evaluation of the biological importance of the tumour was based on the presence or absence of metastases or gross infiltration of adjacent organs. ${ }^{10}$ Thus, a tumour was considered benign if no metastases were found at laparotomy or at pathological examination of the surgical specimen. By this criterion, eight tumours were malignant (four in the pancreas, four in the small intestine), and four benign (all in the pancreas), while the biological importance remained unclear in one extravisceral neuroendocrine 
Details of patients and proliferative activity of tumour tissue

\begin{tabular}{|c|c|c|c|c|c|c|c|c|c|}
\hline $\begin{array}{l}\text { Patient } \\
\text { No }\end{array}$ & Sex & $\begin{array}{l}\text { Age } \\
\text { (years) }\end{array}$ & Tumour site & $\begin{array}{l}\text { Biological } \\
\text { importance }\end{array}$ & $\begin{array}{l}\text { Hormonal } \\
\text { activity }\end{array}$ & $\begin{array}{l}\text { S-phase } \\
(\%)\end{array}$ & $\begin{array}{l}G_{2}-/ M \text {-phase } \\
(\%)\end{array}$ & $\begin{array}{l}\text { Proliferative } \\
\text { index }(\%)\end{array}$ & $\begin{array}{l}\text { Ki67 } \\
\text { score }\end{array}$ \\
\hline 1 & M & 63 & Duodenum & Malignant & Inactive & $26 \cdot 6$ & $9 \cdot 6$ & $36 \cdot 2$ & +++ \\
\hline \multirow[t]{2}{*}{2} & $M$ & 44 & Ileum & Malignant & & nd & nd & nd & nd \\
\hline & & 48 & Mesentery & Metastasis & Inactive & $8 \cdot 0$ & $3 \cdot 4$ & $11 \cdot 4$ & nd \\
\hline 3 & M & 62 & Ileum & Malignant & Carcinoid & $3 \cdot 2$ & $5 \cdot 6$ & $8 \cdot 8$ & + \\
\hline 4 & $\mathrm{~F}$ & $\begin{array}{l}49 \\
49\end{array}$ & $\begin{array}{l}\text { Ileum } \\
\text { Liver }\end{array}$ & $\begin{array}{l}\text { Malignant } \\
\text { Metastasis }\end{array}$ & Carcinoid & $\begin{array}{l}0 . \overline{8} \\
2.9\end{array}$ & $\begin{array}{l}2 \cdot 1 \\
3.9\end{array}$ & $\begin{array}{l}2.9 \\
6.8\end{array}$ & $\stackrel{+}{\text { nd }}$ \\
\hline 5 & $M$ & 49 & $\begin{array}{l}\text { Retro- } \\
\text { peritoneum }\end{array}$ & ? Benign & Inactive & $2 \cdot 8$ & $2 \cdot 4$ & $5 \cdot 2$ & + \\
\hline \multirow[t]{2}{*}{6} & $M$ & 47 & Pancreas & Malignant & Inactive & $5 \cdot 4$ & $3 \cdot 7$ & $9 \cdot 1$ & + \\
\hline & & 47 & Liver & Metastasis & & $9 \cdot 7$ & $8 \cdot 6$ & $18 \cdot 3$ & ++ \\
\hline \multirow[t]{2}{*}{7} & $\mathrm{~F}$ & 44 & Pancreas & Malignant & Inactive & $4 \cdot 0$ & $6 \cdot 4$ & $10 \cdot 4$ & ++ \\
\hline & & 44 & Liver & Metastasis & & $3 \cdot 4$ & $5 \cdot 3$ & $8 \cdot 7$ & + \\
\hline 8 & $\mathrm{~F}$ & 40 & Pancreas & Malignant & Inactive & nd & nd & nd & nd \\
\hline & & 40 & Liver & Metastasis & & $3 \cdot 6$ & $6 \cdot 0$ & $9 \cdot 6$ & ++ \\
\hline 9 & $\mathrm{~F}$ & 61 & Pancreas & Malignant & ?Glucagonoma & $3 \cdot 7$ & $6 \cdot 1$ & $9 \cdot 8$ & + \\
\hline 10 & M & 39 & Pancreas & Benign & Insulinoma & $2 \cdot 8$ & $2 \cdot 8$ & $5 \cdot 6$ & + \\
\hline 11 & $\mathrm{~F}$ & 38 & Pancreas & Benign & Insulinoma & $2 \cdot 4$ & $4 \cdot 0$ & $6 \cdot 4$ & + \\
\hline 12 & $\mathrm{~F}$ & 31 & Pancreas & Benign & VIPoma & 1.9 & $5 \cdot 8$ & $7 \cdot 7$ & + \\
\hline 13 & $\mathrm{~F}$ & 52 & Pancreas & Benign & Gastrinoma & $1 \cdot 4$ & 2.9 & $4 \cdot 3$ & nd \\
\hline
\end{tabular}

$\mathrm{VIP}=$ vasoactive intestinal polypeptide.

nd $=$ not determined.

tumour localised in the parapancreatic retroperitoneum (patient 5). In the latter case no visceral primary tumour was evident over five years of observation including three laparotomies.

In three patients $(4,6$, and 7$)$, both primary tumour and metastases were investigated. In two patients ( 2 and 8 ) only metastases were available for this study.

Proliferative activity was assessed first by DNA flow cytometry. ${ }^{11}{ }^{12} \mathrm{With}$ this method cellular DNA content can be analysed, and cells can be quantified as percentages within the phases $\mathrm{G}_{0}-\mathrm{G}_{1}-$ (presynthesis), $\mathrm{S}-$ (DNA synthesis), and $G_{2} / M-$ (premitosis and mitosis) of the cell cycle. ${ }^{13}$ DNA flow cytometry was performed as described in detail elsewhere. ${ }^{14}$ is Cells were prepared from fresh frozen tumour tissue. DNA content-dependent fluorescence was measured by an ICP 22 cytometer (Phywe, Göttingen, Germany) at $365 \mathrm{~nm}$ excitation. Background debris was corrected, as previously reported, to improve the accuracy of the S-phase fraction. ${ }^{14}$ The coefficient of variation ranged from $1 \cdot 8$ to $5 \cdot 2 \%$.

For this study flow cytometric data on tumour cells in the $\mathrm{S}-$ (DNA synthesis) and the $\mathrm{G}_{2}-/$ $\mathrm{M}$ - (mitosis) phases were added together to give

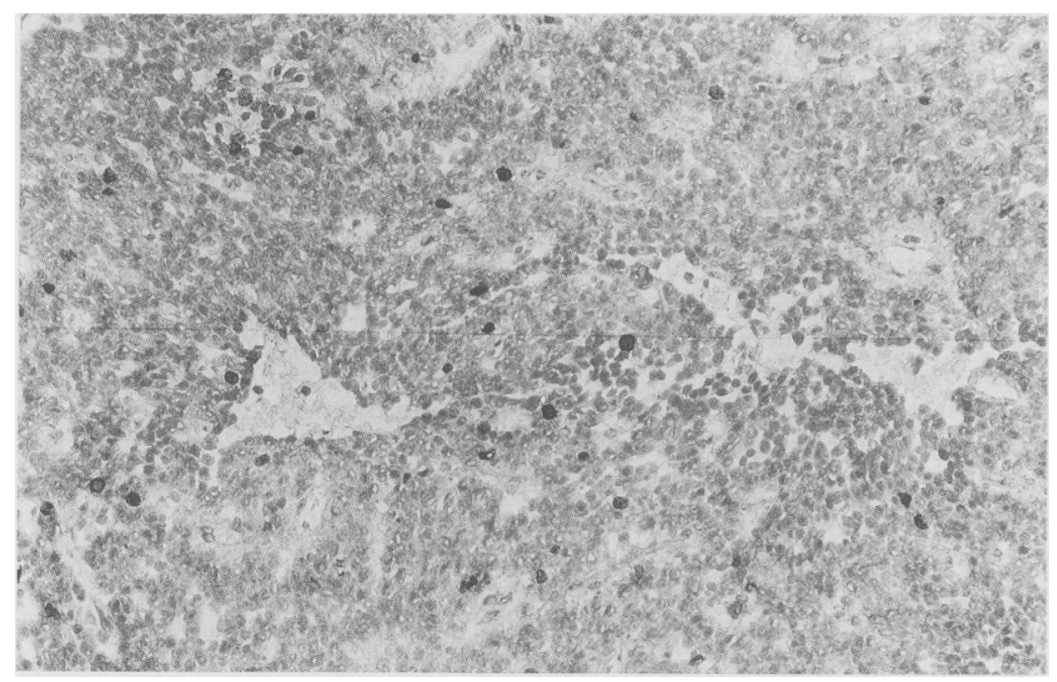

Figure 1: Ki67 immunohistology (score 1+): scattered immunoreactive tumour cells (case 5, extravisceral neuroendocrine tumour). a 'proliferative index.' On the basis of previous experience with many other tumours, ${ }^{15}$ indices were classified into three categories corresponding to low (index $<9 \cdot 5 \%$ ), moderate $(9 \cdot 5-15 \%)$, and high proliferative activity $(>15 \%)$.

In a second approach, the expression of the proliferation antigen Ki67 was studied. This nuclear antigen is present in cells only within the late $G_{1}-, S-, G_{2}-$, and $M-$ phases of the cell cycle but not in resting cells. ${ }^{16}$ Immunohistochemistry was performed on cryostat sections of fresh frozen tumour tissue by using the monoclonal antibody $\mathrm{Ki}^{16}$ (Dianova, Hamburg, Germany) in an indirect streptavidin biotin-peroxidase method.

Ki67 immunoreaction was evaluated under light microscopy at 400 -fold magnification by two independent observers (AvH, BS). The immunoreaction was graded semiquantitatively on the basis of a score between $1+$ and 3+: $1+=$ low (Fig 1), 2+=moderate (Fig 2), and $3+=$ a high proportion (Fig 3 ) of Ki67 immunoreactive tumour cells.

Proliferative activity was correlated with the clinical course in seven patients with malignant gastroenteropancreatic neuroendocrine tumours and in one patient with a non-resectable extravisceral tumour. Postoperative follow up ranged from 12 to 28 months. All four patients with benign pancreatic endocrine tumours were probably cured by local resection. Patient 2 was lost to follow up.

\section{Results}

Individual results are presented in the Table.

DNA FLOW CYTOMETRY

In four small intestinal carcinoids (patients 1-4) the proliferative indices had a wide range. In one duodenal carcinoid (patient 1) the proliferative index was $36 \cdot 2 \%$, corresponding to high proliferative activity. One ileum carcinoid metastatic to the mesentery (patient 2) had an index of $11 \cdot 4 \%$, corresponding to moderate proliferative activity. Two other ileum carcinoids (patients 3 and 4 ), however, had indices of $8.8 \%$ and $2.9 \%$, respectively, as did the liver metastasis of one (patient 4 , index $6 \cdot 8 \%$ ), all reflecting low prolif- 


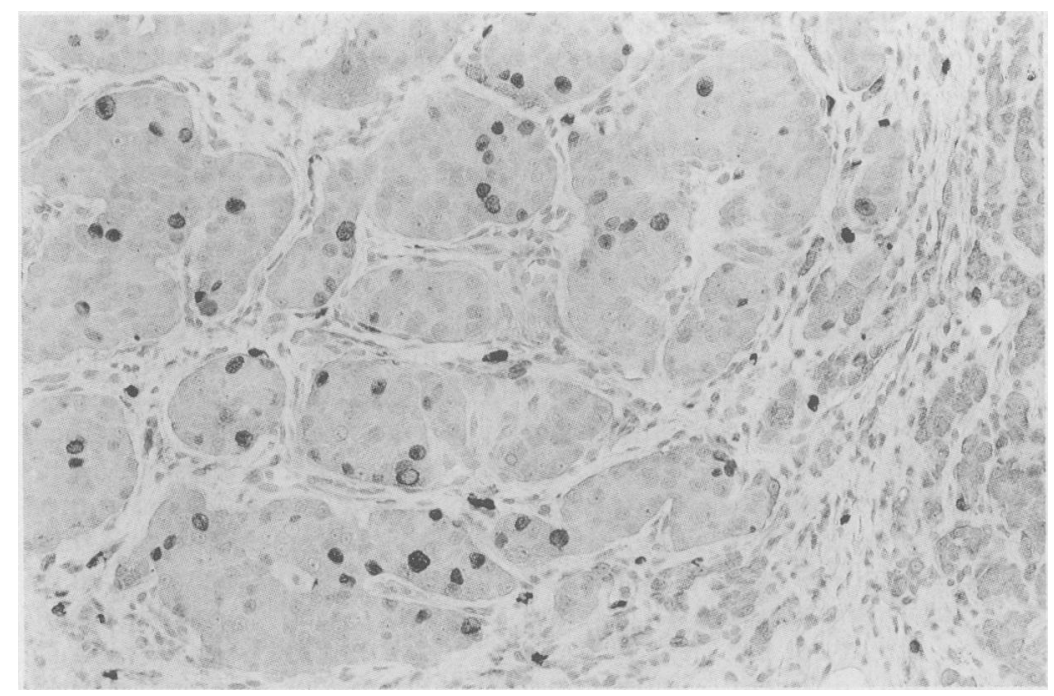

Figure 2: Ki67 immunohistology (score 2+): several immunoreactive tumour cells (case 6, liver metastasis of pancreatic endocrine tumour).

erative activity. The serotonin immunoreactive extravisceral neuroendocrine tumour (patient 5) had an index of $5 \cdot 2 \%$, corresponding to low proliferative activity.

In four endocrine pancreatic tumours with metastases (patients 6-9) indices ranged from $8 \cdot 7$ to $18 \cdot 3 \%$ - that is, from low to high proliferative activity. The liver metastases of two pancreatic tumours had either enhanced (index $18.3 \% v$ $9 \cdot 1 \%$, patient 6$)$ or roughly similar $(8 \cdot 7 \% v$ $10 \cdot 4 \%$, patient 7 ) proliferative activity compared with their respective primary tumours. The proliferative activity indices of the other four endocrine pancreatic tumours (patients 10-13) had a small range, $4 \cdot 3-7 \cdot 7 \%$, all corresponding to low proliferative activity.

\section{Ki67 IMMUNOHISTOCHEMISTRY}

The immunoreaction of the Ki67 antibody with tumour tissue resulted in a positive nuclear staining in a varying proportion of tumour cells (Figs 1-3) and stromal cells. Both cell types were readily distinguishable under light microscopy.

In three small intestinal carcinoids studied by

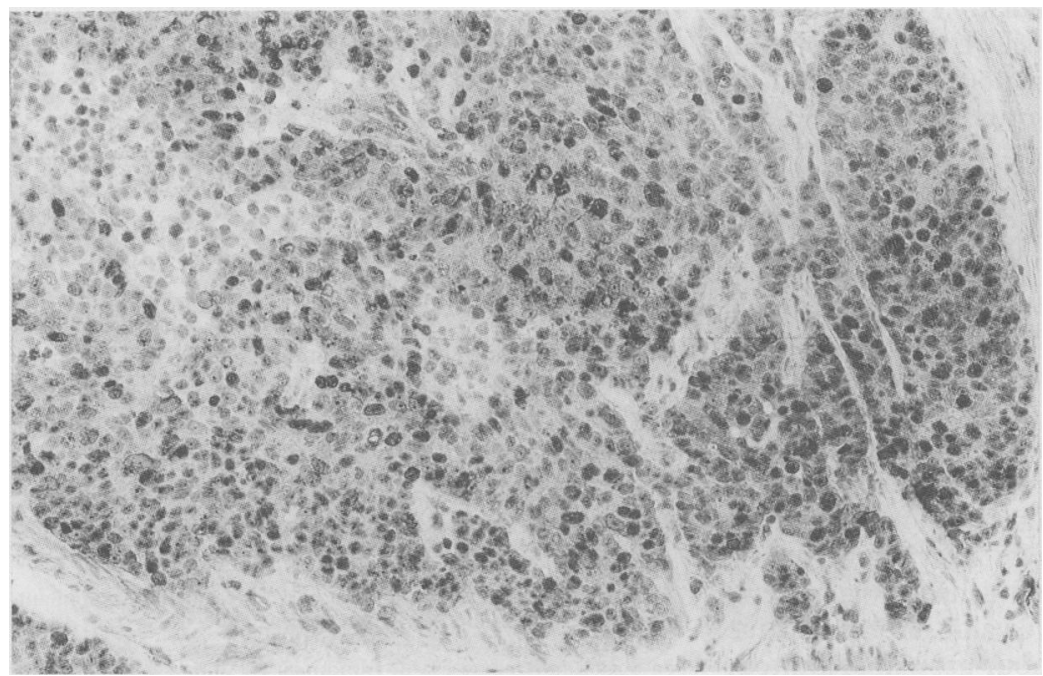

Figure 3: Ki67 immunohistology (score 3+): many immunoreactive tumour cells (case 1, duodenal carcinoid). immunohistology the results were diverse. In patient 1 many tumour cell nuclei were immunoreactive (score $3+$ ), while in patients 3 and 4 only a few tumour cells were positive (score $1+$ ). The extravisceral serotonin immunoreactive neuroendocrine tumour (patient 5) had few positive cells (score $1+$ ).

Three out of four pancreatic endocrine tumours with metastases (patients 6-8) had a moderate number of immunoreactive cells (score $2+$ ), while the fourth (patient 9) had only a few positive cells (score $1+$ ). Three other pancreatic endocrine tumours (patients 10-12) had few immunoreactive tumour cell nuclei (score $1+$ ).

CORRELATION OF RESULTS FROM BOTH METHODS Comparing the results obtained with the two methods, individual Ki67 immunohistological scores are in accord with the flow cytometric data (Fig 4). There was little overlap of results for tumours with borderline low to moderate proliferative activity. But lesions with moderate and high flow cytometric proliferative indices were clearly differentiated from tumours with low proliferative activity (Fig 4).

\section{CORRELATION OF PROLIFERATIVE ACTIVITY AND} CLINICAL COURSE

High proliferative activity (two patients) correlated in one patient (No 1) with a short postoperative course of 11 months until death from the progressing tumour. The other patient (No 6) was alive 28 months after surgery but with progression of liver metastases.

Moderate proliferative activity (three patients) correlated in two patients with 12 months (No 9) and 25 months (No 8) of postoperative survival until they died of their disease. One patient (No 7) was alive after 27 months of follow up, but with progression of tumour disease.

Low proliferative activity (three patients) correlated in one patient (No 4) with a 13 year

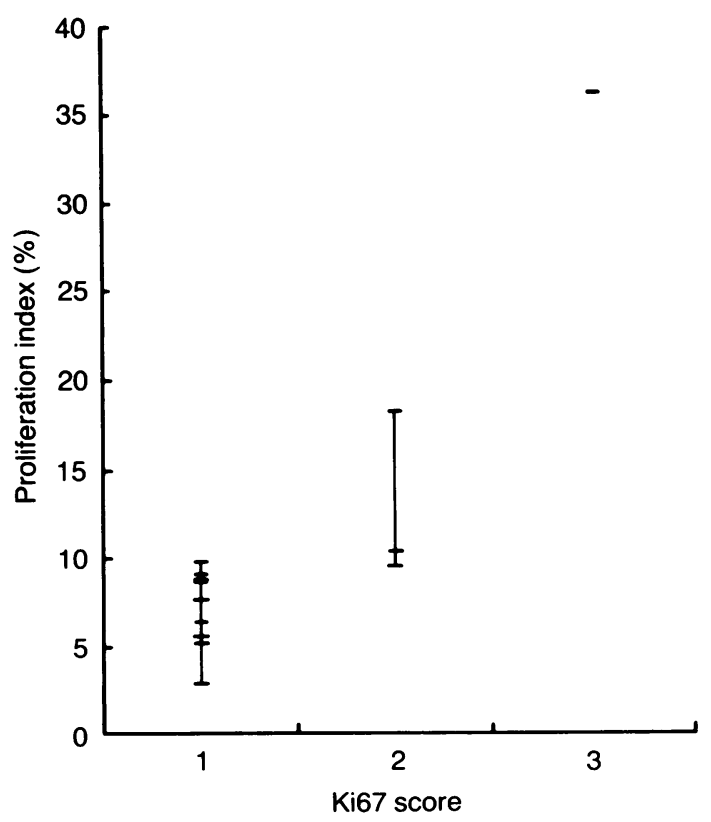

Figure 4: Correlation of individual DNA flow cytometric and Ki67 scoring results. 
course before she was operated on. During this long period, virtually no local progression was observed, but liver metastases and carcinoid syndrome finally developed. She was alive 28 months after surgery. Similarly, slow tumor growth was monitored for 60 months in patient 5 , who was alive 25 months after a second partial tumour resection (this tissue was studied). One patient (No 3) was alive after 17 months.

\section{Discussion}

The growth of gastroenteropancreatic neuroendocrine tumours is as yet largely unstudied. Articles in textbooks ${ }^{1819}$ and other reviews ${ }^{20}$ emphasise that slow growth and low mitotic rate are typical. In contrast to these empirical descriptions, we found the proliferative activity of the tumours, as determined by two different methods, to be heterogeneous. Although the number of tumours we studied was limited, some trends may be recognised with respect to the tumour's hormonal activity and proliferation. They do, however, require comment.

Comparing gastroenteropancreatic neuroendocrine tumours on the basis of the presence or absence of hormone activity showed that five of six small intestinal carcinoid and pancreatic endocrine tumours with no hormone activity had greater proliferative activity than tumours with hormone activity. We also observed, however, an extravisceral carcinoid tumour without hormone activity that had low proliferative activity, similar to a pancreatic endocrine tumour without hormone activity studied previously." Thus, although gastroenteropancreatic neuroendocrine tumours without hormone activity (corresponding to loss of endocrine cell differentiation) tend to have higher proliferative activity than tumours with hormone activity (reflecting persistence of functional differentiation), the individual growth behaviour escapes generalisation.

Comparing these neuroendocrine tumours on the basis of their growth behaviour showed that seven of eight malignant tumours had greater proliferative activity than all five benign tumours. The limitations, however, of this are shown by our further observation of an ileal carcinoid tumour with multiple metastases but a very low proliferative index. Thus, although malignant tumours tend to have higher proliferative activity than benign tumours, no generalisations can be made on the growth behaviour of the individual tumour.

Liver metastases had either enhanced (two cases) or similar (one case) proliferative activity as their respective primary gastroenteropancreatic neuroendocrine tumour. This may signify a tendency to enhanced proliferative activity in metastases, as has been reported for other tumours. ${ }^{22}$

Proliferative activity as determined by our approach in vitro may be expected to indicate the growth behaviour of the tumour in vivo. Indeed, a correlation of our results in vitro with the clinical course was established for several patients. But the predictive value of proliferative activity for the rate of tumour growth is limited, as growth only results if the rate of cell proliferation exceeds the rate of spontaneous tumour cell death. ${ }^{22}$ Moreover, spontaneous variation of proliferative activity may occur as time goes on. ${ }^{22}$

Apart from extrapolation of tumour growth rate, information on proliferative activity of individual tumours may have more important implications for the treatment of the patient. Since the biology of tumour growth is a major factor affecting the response to chemotherapy, ${ }^{23}$ the heterogeneous proliferative activity of these tumours found in this study may explain, at least in part, the heterogeneous response to chemotherapy of gastroenteropancreatic neuroendocrine tumours. ${ }^{5}$ Among the cytostatic drugs used, streptozotocin, 5-fluorouracil, and anthracyclines are currently recommended. ${ }^{519}$ As these drugs act mainly (but not exclusively) on cells in the S-phase of the cell cycle, ${ }^{22}{ }^{23}$ a small percentage of tumour cells within the S-phase means a limited number of target cells on which the drug can act. Thus, the investigation of proliferative activity might be a useful tool for identifying patients who are suitable for antineoplastic drug treatment.

At first sight, DNA flow cytometry seems to be a more reliable diagnostic test than $\mathrm{Ki67}$ immunohistochemistry for determining proliferative tumour activity by providing numerical data. But, as the essential accuracy of flow cytometric S-phase fraction measurements is dependent on individual laboratory procedures and a low coefficient of variation $(<5 \%)$, the interpretation of the numerical data obtained should be considered critically. ${ }^{12}$ If DNA flow cytometry is not available, immunohistochemistry for the Ki67 defined nuclear proliferation antigen may be an alternative. In our experience subjective scoring of Ki67 immunohistochemistry achieved results comparable with those obtained with DNA flow cytometry by differentiating tumours with low, moderate, and high proliferative activity.

In view of the natural heterogeneity in the growth kinetics of gastroenteropancreatic neuroendocrine tumours, as shown by adequate techniques, the diagnostic value of estimating the proliferative activity of the individual tumour for a rational therapeutic concept should be investigated prospectively.

We wish to thank Mrs I Appel, Mrs I Müller, Mrs Ch Koch, Mrs U Sturm, and Mr D Haag for their skilful technical assistance.

1 Grube D. The endocrine cells of the digestive system: amines, peptides, and modes of action. Anat E mbryol 1986; 175: 157 62 .

2 Kowlessar OD. The carcinoid syndrome. In: Sleisenger MH Fordtran JS, eds. Gastrointestinal diseases. 4th ed. Philadelphia: W B Saunders, 1989: 1560-70.

3 Delvalle J, Yamad AT. Secretory tumors of the pancreas. In Sleisenger MH, Fordtran JS, eds. Gastrointestinal diseases. 4th ed. Philadelphia: W B Saunders, 1989: 1884-900.

4 Elouar-Blanc L, Mignmon M, Lewin JMJM. Culture de tumeurs endocrines gastroentero-pancretiques: apports actuels et perspectives d'avenir. Gastroenterol Clin Biol 1988; 12: $565-72$.

5 Kvols LK, Buck M. Chemotherapy of endocrine malignancies: a review. Semin Oncol 1987; 14: 343-53.

6 O'Donell LJ, Farthing MJG. Therapeutic potential of a long acting somatostatin analogue in gastrointestinal disease. Gu 1989; 30: 1165-72.

7 Öberg K, Norheim I, Lindh E, et al. Treatment of malignan carcinoid tumors with human leucocyte interferon: long term results. Cancer Treat Rep 1986; 70: 1279-304.

7a Eriksson B, Skogseid B, Lundquist G, Wide L, Wilander E, Öberg $K$. Medical treatment and long-term survival in prospective study of 84 patients with endocrine pancreatic tumors. Cancer 1990; 65: 1883-90. 
8 Schuppert F, Schöber Ch, Schmoll E, et al. Interferon alpha-2b in patients with neuroendocrine gut tumors (carcinoids) and Endocrinol 1990; 122 (suppl 1): 45.

9 Lloyd RV. Immunohistological localization of chromogranin and neuron-specific enolase in gastroenteropancreatic and neuron-specific enolase in gastroenteropan

10 Klöppel G, Heitz PhU. Pancreatic endocrine tumors. Pathol Res Pract 1988; 183: 155-68.

11 Quinn CM, Wright NA. The clinical assessment of proliferation and growth in human tumours: evaluation of methods and applications as prognostic variables. $\mathcal{F}$ Pathol $1990 ; 160$ : 93-102

12 Shapiro HM. Flow cytometry of DNA content and other indicators of proliferative activity. Arch Pathol Lab Med 1989; 113: 591-7.

13 Baserga R. The cell cycle. N Engl f Med 1981; 304: 453-9.

14 Haag D. Flow microfluorometric deoxyribonucleic acid (DNA) analysis supplementing routine histopathologic diag(DNA) analysis supplementing routine histopathologic

15 Feichter GE, Goerttler K, Haag D, et al. DNA measurement of malignant tumors by impulse cytophotometry: principles malignant tumors by impulse cytophotometry: principles
and significance in the assessment of growth and degree of abnormality. Disch Med Wochenschr 1984; 109: 738-44.

16 Gerdes J, Schwab U, Lemke H, Stein H. Production of a mouse monoclonal antibody reactive with a human nuclea antigen associated with cell proliferation. Int $\mathcal{f}$ Cancer 1983 31: $13-20$.

17 Gerdes J, Lemke H, Baisch H, Wacker HH, Schwab U, Stein $H$. Cell cycle analysis of a cell proliferation associated human nuclear antigen defined by the monoclonal antibody $\mathrm{Ki}-67 . \mathcal{F}$ Immunol 1984; 133: 1710-5.
18 Sindelar WF. Cancer of the small intestine. In: DeVita VT Jr, Hellman S, Rosenberg SA, eds. Cancer. Principles and practice of oncology. 3rd ed. Philadelphia: Lippincott, 1989 875-94.

19 Metcalfe MS, Macdonald JS. Uncommon pancreatic tumors. In: Williams CJ, Krishorian JG, Green MG, Raghavan D (eds). Textbook of uncommon tumors. Chichester: Wiley, 1988: 471-89.

20 Mazzaferri EL, O’Dorisio TM. Endocrine tumors - special problems in diagnosis and management. Semin Oncol 1987; 14: $235-6$

21 von Herbay A, Sieg B, Otto HF. Solid-cystic tumor of the pancreas: an endocrine neoplasm? Virchows Arch [A] 1990 416: 535-8.

22 Tannock IF. Principles of cell proliferation: cell kinetics. In: DeVita VT Jr, Hellman S, Rosenberg SA, eds. Cancer. Principles and practice of oncology. 3rd ed. Philadelphia: Lippincott, 1989: 3-13.

23 De Vita VT, Jr. Principles of chemotherapy. In: DeVita VT, Jr, Hellman S, Rosenberg SA, eds. Cancer. Principles and practice of oncology. 3rd ed. Philadelphia: Lippincott, 1989: practice of

\section{Note added in proof:}

Since this paper was accepted we have investigated a further 10 gastroenteropancreatic neuroendocrine tumour specimens. The additional data confirm that the individual proliferative activity of these endocrine tumours is heterogeneous. 